Research article

Open Access

\title{
Diagnostic value of antibodies against a modified citrullinated vimentin in rheumatoid arthritis
}

\author{
Christian Dejaco ${ }^{1,2}$, Werner Klotz ${ }^{1}$, Heike Larcher ${ }^{1}$, Christina Duftner ${ }^{1}$, Michael Schirmer $^{2}$ and \\ Manfred Herold 1
}

\author{
${ }^{1}$ Clinical Department of Internal Medicine, Division of General Internal Medicine, Innsbruck Medical University, Anichstrasse 35, 6020 Innsbruck, \\ Austria \\ ${ }^{2}$ General Hospital of the Elizabethenians, Voelkermarkterstrasse 15-19, 9020 Klagenfurt, Austria \\ Corresponding author: Manfred Herold, manfred.herold@uibk.ac.at
}

Received: 5 May 2006 Revisions requested: 31 May 2006 Revisions received: 20 Jun 2006 Accepted: 7 Jul 2006 Published: 19 Jul 2006

Arthritis Research \& Therapy 2006, 8:R119 (doi:10.1186/ar2008)

This article is online at: http://arthritis-research.com/content/8/4/R119

(c) 2006 Dejaco et al.; licensee BioMed Central Ltd.

This is an open access article distributed under the terms of the Creative Commons Attribution License (http://creativecommons.org/licenses/by/2.0), which permits unrestricted use, distribution, and reproduction in any medium, provided the original work is properly cited.

\begin{abstract}
Antibodies directed against citrullinated vimentin are members of the family of autoantibodies reactive with citrullinated proteins and are among the most specific serological markers for the diagnosis of rheumatoid arthritis (RA). This study was performed to test the diagnostic value of a newly developed enzyme-linked immunosorbent assay (ELISA) for the detection of antibodies against a genetically modified citrullinated vimentin (anti-MCV) in comparison with a second-generation anti-cyclic citrullinated peptides (anti-CCP2) ELISA test system. Blinded sera from 631 patients (409 consecutive out-patients and 222 randomly selected stored sera) with RA $(n=164)$ and non-RA (osteoarthritis [ $n=120]$, polymyalgia rheumatica/giant cell arteritis $[n=80]$, spondyloarthritis $[n=36]$, and other inflammatory rheumatic or non-inflammatory disease $[n=67]$ ) were tested for the presence of anti-MCV and anti-CCP2 antibodies according to the manufacturers' instructions. The diagnostic performance of the anti-MCV was comparable with the anti-CCP2 assay for the diagnosis of RA according to the

calculated area under the curve $(0.824 ; 95 \%$ confidence interval $(\mathrm{Cl}) 0.778-0.870$ versus $0.818 ; 95 \% \mathrm{Cl} 0.767-0.869)$ as analysed by receiving operating characteristic curve. When categorised with a cutoff value of $20.0 \mathrm{U} / \mathrm{ml}$ (as recommended by the manufacturer), sensitivity and specificity of the anti-MCV ELISA were $69.5 \%(95 \% \mathrm{Cl} 61.9 \%-76.5 \%)$ and $90.8 \%$ (86.9\%-93.8\%), respectively, compared with $70.1 \%(62.5 \%-$ $77.0 \%)$ and $98.7 \%(96.7 \%-99.6 \%)$ of the anti-CCP2 assay. Using the cutoff values of $19.0 \mathrm{U} / \mathrm{ml}$ and $81.5 \mathrm{U} / \mathrm{ml}$ for the antiMCV test to obtain a sensitivity and specificity identical to the anti-CCP2 assay, showed a reduced specificity $(89.8 \%$; $85.8 \%-92.9 \%)$ and sensitivity (53.7\%; 45.7\%-61.5\%), respectively, of the anti-MCV ELISA compared with the antiCCP2 test. In conclusion, the serum ELISA testing for anti-MCV antibodies as well as the anti-CCP-2 assay perform comparably well in the diagnosis of RA. In the high-specificity range, however, the anti-CCP2 assay appears to be superior to the anti-MCV test.
\end{abstract}

\section{Introduction}

Rheumatoid arthritis (RA) is the most common inflammatory joint disease, with a prevalence between $0.5 \%$ and $1 \%$ worldwide [1]. In most patients, diagnosis of RA is based on the criteria proposed by the American College of Rheumatology (ACR) in 1987 consisting of clinical symptoms and radiological findings, whereas the only laboratory test included is the serum rheumatoid factor (RF) determination [2]. The ACR cri- teria, however, were primarily developed as classification criteria in established disease, and shortcomings in RA patients with recent-onset disease have now become evident [3]. Currently available data suggest that the diagnosis of RA can benefit from testing for antibodies to citrulline-containing peptides such as antiperinuclear factors (APFs), antifillagrin antibodies, antikeratin antibodies (AKAs), and anti-cyclic citrullinated peptides (anti-CCPs) [4-7]. Due to practical inconvenience, APF

$\overline{\mathrm{ACR}}=$ American College of Rheumatology; $\mathrm{AKA}=$ antikeratin antibody; anti-CCP $=$ anti-cyclic citrullinated peptide; anti-MCV $=$ anti-modified citrullinated vimentin; $\mathrm{APF}=$ antiperinuclear factors; $\mathrm{AUC}=$ area under the curve; $\mathrm{Cl}=$ confidence interval; $\mathrm{ELISA}=$ enzyme-linked immunosorbent assay; $\mathrm{lg}=$ immunoglobulin; IgM-RF = immunoglobulin M-rheumatoid factor; OA = osteoarthritis; PMR/GCA = polymyalgia rheumatica and/or giant cell arteritis; $\mathrm{RA}=$ rheumatoid arthritis; $\mathrm{RF}=$ rheumatoid factor; $\mathrm{ROC}=$ receiving operating characteristic; $\mathrm{SD}=$ standard deviation; $\mathrm{SpA}=\mathrm{spondyloar-}$ thritis. 
Table 1

\begin{tabular}{lc} 
Clinical characteristics of patients with rheumatoid arthritis ( \\
= 164) \\
\hline Age & $60.4(12.0)^{\mathrm{a}}$ \\
Female, $n(\%)$ & $140(85.4)$ \\
Disease duration $(n=153)$ & \\
$\quad<1$ year, $n(\%)$ & $23(15.0)$ \\
$1-5$ years, $n(\%)$ & $45(29.4)$ \\
$>5$ years, $n(\%)$ & $85(55.6)$ \\
DAS-28 ( $n=69)$ & $3.3(1.5)^{\mathrm{a}}$ \\
Swollen joint count $(n=137)$ & $1(0-23)^{\mathrm{b}}$ \\
Tender joint count $(n=92)$ & $1(0-28)^{\mathrm{b}}$ \\
Patients' global assessment (VAS) $(n=56)$ & $23.2(23.5)^{\mathrm{a}}$ \\
ESR (mm/first hour) $(n=152)$ & $28.8(19.3)^{\mathrm{a}}$ \\
CRP (mg/l) ( $n=160)$ & $13.9(23.2)^{\mathrm{a}}$ \\
IL-6 (pg/ml) ( $n=74)$ & $111.0(292.2)^{\mathrm{a}}$
\end{tabular}

aMean (standard deviation). bMedian (range). CRP, C-reactive protein (normal values 0-6 mg/l); DAS, disease activity score; ESR, erythrocyte sedimentation rate (normal values $0-10 \mathrm{~mm} /$ first hour); IL-6, interleukin-6 (normal values $0-3 \mathrm{pg} / \mathrm{ml}$ ); VAS, visual analogue scale (range $0-100 \mathrm{~mm}$ ).

was never introduced into clinical routine, whereas detection of AKA by indirect immunofluorescence was among the main laboratory tests used before anti-CCP enzyme-linked immunosorbent assay (ELISA) kits became commercially available. The anti-CCP ELISA is based on highly purified synthetic peptides from dedicated libraries containing modified arginine residues (citrulline) serving as antigens, has a specificity comparable with AKA, and is more specific than APF and RF testing [8-10].

Historically, anti-Sa antibodies were first identified in a French Canadian patient whose name began with Sa. The reactivity of these antibodies was found to be highly specific for RA [11]. Subsequent studies confirmed the high degree of RA specificity, which exceeds 95\%, in several populations tested [12$15]$. The sensitivity of this antibody varied with the stage of the disease tested, ranging from $20 \%-25 \%$ in early RA cohorts to $47 \%$ in patients with more established disease [14,15]. The $\mathrm{Sa}$ antigen, originally derived from placental tissue, has recently been identified as citrullinated forms of vimentin $[11,16]$. Vimentin is an intermediate filament that is widely expressed in mesenchymal cells and macrophages and is easily detectable in synovium and fibroblast-like synoviocytes [1719]. In vivo, vimentin is usually not in a citrullinated state, but deimination of this protein occurs in macrophages undergoing apoptosis. Anti-citrullinated vimentin antibodies may then emerge as a consequence of inadequate clearance of apoptotic material in patients with RA [20].
In this study, we tested the value of a newly developed ELISA for the detection of antibodies against a genetically modified citrullinated vimentin (anti-MCV) in comparison with an antiCCP2-based ELISA system for the diagnosis of RA.

\section{Materials and methods Patients}

Consecutive sera ( $n=409$ ) were obtained between October 2005 and February 2006 from patients visiting the rheumatic outpatient clinic (Clinical Department of Internal Medicine) of the Innsbruck Medical University (Innsbruck, Austria) and stored until final use. Frozen sera $(n=222)$ from patients with known inflammatory rheumatic diseases obtained between 2003 and 2005 were randomly selected and included in the analysis. The final diagnosis was used as the reference standard and was obtained by chart review. Unclear cases were discussed by three investigators ( $\mathrm{C}$ Dejaco, $\mathrm{C}$ Duftner, and $\mathrm{MH}$ ) and excluded if no definite diagnosis could be reached (Additional File 1). One hundred and sixty-four patients were diagnosed as having RA that met at least four out of the seven criteria according to the 1987 ACR classification [2]. In the rest of the cases, the following diagnoses were made: osteoarthritis (OA $[n=120]$ ), polymyalgia rheumatica and/or giant cell arteritis (PMR/GCA $[n=80]$ ) [21], spondyloarthritis (SpA [ $n$ $=36$ ], including psoriatic arthritis [ $n=10$ ] [22], ankylosing spondylitis [ $n=9$ ] [23], and colitis-associated/undifferentiated SpA [ $n=17]$ ] [24], or other inflammatory rheumatic or non-inflammatory disease $(n=67$; connective tissue disease [ $n=12]$, crystal arthopathy [ $n=4]$, fibromyalgia [ $n=9]$, mechanical back pain or enthesopathy $[n=29]$, virus infection-associated arthralgia $[n=6]$, and myelodysplastic syndrome $[n=7])$. Demographic, clinical, and serological data of patients with RA were obtained by chart review (Table 1). Also, data on the serum levels of immunoglobulin (lg) M-RF (IgM-RF), which were routinely determined by a nephelometric method (normal values $0-13 \mathrm{U} / \mathrm{ml}$ ), were retrieved by chart review. The mean ages of patients with RA and patients with non-RA were $60.4( \pm 12.0)$ and $58.5( \pm 15.7)$ years (not significant), respectively. In the RA group, there were slightly more women (85.4\%) than in the control group $(76.2 \% ; p=$ 0.026 according to the $\chi^{2}$ test with Yates correction). Patients with RA were under current treatment with single or combined disease-modifying anti-rheumatic drugs (methotrexate $[n=$ 95], leflunomide [ $n=21]$, azathioprine $[n=3]$, sulfasalazine [ $n$ $=13]$, hydroxychloroquine $[n=13]$, cyclosporine $\mathrm{A}[n=2]$, and Escherichia coli extract OM-89 $[n=8])$ alone or in combination with corticosteroids $(n=84)$, and tumour necrosis factor- $\alpha$ blocking agents (infliximab $[n=2]$, etanercept $[n=6]$, adalimumab [ $n=10]$, or anakinra $[n=2]$ ). No association was found between disease duration and markers of disease activity (data not shown). The study was approved by the local ethics committee. Written and informed consent was obtained from each patient. 
Figure 1



Comparison of the diagnostic values of the anti-modified citrullinated vimentin (MCV) and the anti-cyclic citrullinated peptide (CCP) 2 assay. Receiver operating curves of the anti-MCV and (second-generation) anti-CCP antibodies are shown. The sensitivity of each test is plotted against one minus specificity for varying cutoffs (values lower than the cutoff were considered negative, and other values were considered positive) $(n=467)$.

\section{Anti-CCP2 and anti-MCV testing}

Anti-MCV and anti-CCP2 testing was performed in an investigator-blinded fashion. Anti-CCP2 antibody reactivity was tested using a commercially available automated ELISA (EliA ${ }^{\mathrm{TM}}$ CCP Assay;Phadia GmbH, Freiburg, Germany) on a ImmunoCAP100 automatic analyzer (Phadia AB, Uppsala, Sweden) according to the manufacturer's recommendations. Values of $10.0 \mathrm{U} / \mathrm{ml}$ or greater were considered to be positive. Anti-MCV antibodies were measured using a recently launched and now commercially available ELISA (kindly provided by ORGENTEC Diagnostica GmbH, Mainz, Germany) according to the manufacturer's instructions [25]. In brief, serum samples were diluted 1:100 and incubated on MCVcoated microtiter wells for 30 minutes at room temperature on a horizontal shaking platform (100/second). Plates were washed three times and incubated with peroxidase-labeled anti-human IgG-conjugate for 15 minutes. 3,3',5,5'-Tetramethylbenzidine substrate was incubated for 15 minutes after additional washing. Color development was stopped with $1 \mathrm{M} \mathrm{HCl}$ solution, and the optical density of each well was measured with an Anthos 2020 microwell photometer (Anthos Labtec Instruments $\mathrm{GmbH}$, Wals, Austria). Results are expressed in $\mathrm{U} / \mathrm{ml}$ using a simple point-to-point curve-fitting method. Values of $20.0 \mathrm{U} / \mathrm{ml}$ or greater were considered to be abnormal according to manufacturer's recommendations. This cutoff was determined in a previous study of 232 healthy blood donors performed by ORGENTEC Diagnostica $\mathrm{GmbH}$ and comprises two standard deviations (SDs) of the mean antiMCV titer in this cohort (according to the user manual of the anti-MCV ELISA provided by ORGENTEC Diagnostica GmbH and personal communication).

\section{Statistical analysis}

Distributions of laboratory test results are described as the percentage per category for qualitative items and as mean ( \pm $\mathrm{SD}$ ) or median (and range) for quantitative items as stated. For anti-CCP2 and anti-MCV, the receiving operating characteristic (ROC) curve was constructed by plotting sensitivity against one minus specificity (1 - specificity), varying the cutoffs $[9,26]$. Diagnostic values of anti-MCV, anti-CCP2, and IgM-RF are described as sensitivity and specificity with 95\% confidence interval $(\mathrm{Cl})$. To compare quantitative data, the MannWhitney $U$ and the Kruskal-Wallis tests (for multiple comparisons) were performed using the SPSS program, version 11.0 (SPSS Inc., Chicago, IL, USA).

\section{Results}

\section{Patient characteristics}

Sera from 631 patients were included in the study. All sera were subjected to anti-MCV and anti-CCP testing. Sera from 170 patients (26.9\%) were anti-MCV-positive (using the recommended cutoff value of $20.0 \mathrm{U} / \mathrm{ml}$ ), whereas those from $137(21.7 \%)$ tested positive in the anti-CCP2 assay (recommended cutoff value of $10.0 \mathrm{U} / \mathrm{ml}$ ). Anti-MCV and anti-CCP2 were significantly, but not perfectly, correlated with each other (correlation coefficient $=0.594 ; p<0.001$ using Spearman's rank correlation coefficient). In 467 patients, a definite clinical diagnosis (164 patients with RA and 303 with non-RA) was available, and thus these diagnoses were included in the final analysis (Additional File 1). Data on IgM-RF were available in $415(88.9 \%)$ out of these 467 patients, and 178 (42.9\%) were positive for IgM-RF.

\section{Diagnostic value of anti-MCV and anti-CCP2 testing}

Patients with RA had higher serum titers of anti-MCV antibodies (median $101.0 \mathrm{U} / \mathrm{ml}$; range 2-1,094) than patients with OA (7.0 U/ml; 1-87), PMR/GCA (6.9 U/ml; 2-101), SpA (7.0 $\mathrm{U} / \mathrm{ml} ; 2-39)$, and other inflammatory rheumatic or non-inflammatory diseases $(8.0 \mathrm{U} / \mathrm{ml} ; 2-101 ; p<0.001$ for each comparison according to the Mann-Whitney $U$ test).

For direct comparison of the diagnostic values of the anti-MCV and the anti-CCP2 assays, we performed an ROC analysis. The calculated area under the curve (AUC) was comparable between the anti-MCV $(0.824 ; 95 \% \mathrm{Cl} 0.778-0.870)$ and the anti-CCP2 ELISA (0.818; 0.767-0.869) (Figure 1).

For comparing the sensitivity and specificity of the two tests, we used not only the recommended cutoff value of $20.0 \mathrm{U} / \mathrm{ml}$ for the anti-MCV ELISA, but also two additional cutoffs, namely 19.0 and $81.5 \mathrm{U} / \mathrm{ml}$. The results are summarised in 
Table 2

\begin{tabular}{|c|c|c|c|}
\hline & Cutoff (U/ml) & $\begin{array}{l}\text { Sensitivity (\% } \\
{[95 \% \text { Cl] })}\end{array}$ & $\begin{array}{c}\text { Specificity (\% } \\
{[95 \% \text { Cl] })}\end{array}$ \\
\hline \multirow[t]{3}{*}{ Anti-MCV } & $20.0^{a}$ & $69.5(61.9-76.5)$ & $90.8(86.9-93.8)$ \\
\hline & $19.0^{\mathrm{b}}$ & $70.1(62.5-77.0)$ & $89.8(85.8-92.9)$ \\
\hline & $81.5^{c}$ & $53.7(45.7-61.5)$ & $98.7(96.7-99.6)$ \\
\hline Anti-CCP2 & $10.0^{a}$ & $70.1(62.5-77.0)$ & $98.7(96.7-99.6)$ \\
\hline
\end{tabular}

aRecommended by the manufacturer. Cutoff with identical sensitivity ${ }^{b}$ and specificityc ${ }^{c}$ compared with the anti-CCP2 test, respectively.

anti-CCP2, second-generation anti-cyclic citrullinated peptide; antiMCV, anti-modified citrullinated vimentin; $\mathrm{Cl}$, confidence interval.

Table 2. At the cutoff of $19.0 \mathrm{U} / \mathrm{ml}$, both tests had an identical sensitivity, but the specificity of the anti-MCV was reduced. In contrast, when a cutoff of $81.5 \mathrm{U} / \mathrm{ml}$ was used in order to obtain an equal specificity for both assays, the anti-MCV ELISA demonstrated lower sensitivity than the anti-CCP2 test.

With respect to RA patients with recent onset of disease $(<1$ year; $n=23$ ), the sensitivity of the anti-MCV (cutoff $20.0 \mathrm{U} / \mathrm{ml}$ ) and anti-CCP2 assays were both lower $(62.5 \%$; $40.6 \%$ $81.2 \%)$ when compared with RA patients with established disease.

The diagnostic performances of the anti-MCV and the antiCCP2 tests were similar in the consecutive cohort that included 49 patients with RA $(29.9 \%$ out of all patients with RA) and 223 patients with non-RA (73.6\% out of all patients with non-RA) compared with the total cohort, with a calculated AUC of $0.809(0.725-0.893)$ for the anti-MCV ELISA and $0.843(0.765-0.922)$ for the anti-CCP2 test. With the recommended cutoff values of $20.0 \mathrm{U} / \mathrm{ml}$ for the anti-MCV test and $10.0 \mathrm{U} / \mathrm{ml}$ for the CCP2 ELISA, both assays showed a sensitivity of $65.3 \%(50.4 \%-78.3 \%)$ to detect patients with RA; however, the specificity of the anti-MCV test $(91.5 \% ; 87.0 \%-$ 94.8\%) was lower than that of the anti-CCP2 ELISA (98.7\%; $96.1 \%-99.7 \%)$. Taking the cutoff value of $81.5 \mathrm{U} / \mathrm{ml}$ at which the anti-MCV and the anti-CCP2 assays had identical specificities revealed the former assay to have lower sensitivity $(49.0 \%$; 34.4\%-63.7\%) in comparison with the latter.

Sensitivity and specificity of IgM-RF testing for the diagnosis of RA was $76.1 \%(68.6 \%-82.5 \%)$ and $77.7 \%(72.1 \%-$ $82.7 \%)$, respectively, whereas in patients with early disease, IgM-RF revealed a sensitivity of $68.2 \%(45.1 \%-86.1 \%)$.

\section{Discussion}

There is growing evidence that therapeutic intervention early in the course of RA leads to more efficient disease control, less joint damage, and better prognosis of disease outcome.
Therefore, specific laboratory tests are desirable to help in the early differentiation of RA and other forms of rheumatic joint and connective tissue disease [14,27-29]. To date, a number of reports have demonstrated the high diagnostic value of antibodies directed against citrullinated proteins in the diagnosis of RA. Although the specificity was more than $90 \%$ in most studies, the sensitivity of the same antibodies varied between $33 \%$ and $87.2 \%$, possibly reflecting diverse genetic backgrounds and/or methodological differences in diverse antigen preparations and detection techniques applied [30]. The diagnostic value of the anti-CCP2 test in this report was within the range of these earlier publications [7].

Anti-citrullinated vimentin antibodies have previously been detected in $23 \%-43 \%$ of patients with RA but in less than $8 \%$ of patients with non-RA and healthy controls by immunoblotting $[11,13,15]$. The objective of this study was to investigate the diagnostic accuracy of a novel and commercially available ELISA system for the detection of antibodies against a modified citrullinated vimentin (anti-MCV) in a large cohort of patients with confirmed diagnoses of RA and non-RA in direct comparison with the anti-CCP2 assay. As shown in Figure 1, the ROC analysis revealed a comparable overall diagnostic performance of the anti-MCV and anti-CCP2 ELISAs (AUCs of 0.824 and 0.818 , respectively). However, the curves of both tests cross each other, and in the high-specificity range, which is clinically of greatest interest, the anti-CCP2 assay is the more sensitive test, whereas in the low-specificity range, the anti-MCV ELISA has a higher sensitivity. Indeed, taking the cutoff value of $81.5 \mathrm{U} / \mathrm{ml}$ to obtain identical specificity values for both test systems, the sensitivity of the anti-MCV assay $(53.7 \% ; 45.7 \%-61.5 \%)$ was significantly reduced (as the 95\% Cl did not include the corresponding sensitivity of the anti-CCP2 test). Using the cutoff of $19.0 \mathrm{U} / \mathrm{ml}$ with identical sensitivities of both assays resulted in a lower specificity of the anti-MCV test $(89.8 \% ; 85.8 \%-92.9 \%)$ compared with results from previous reports of anti-citrullinated vimentin and the antiCCP2 assay [31]. Because a consecutive cohort of patients best reflects the number of patients with RA and non-RA seen in clinical routine, we analysed the performance of the antiMCV test in this group separately. However, the diagnostic performance of the anti-MCV and anti-CCP2 ELISAs in this consecutive group did not differ from that in the entire cohort.

In patients with early course of disease, the sensitivity of the anti-MCV ELISA was lower at the recommended cutoff of 20.0 $\mathrm{U} / \mathrm{ml}$ compared with those with long-standing RA but was equivalent to that of the anti-CCP2 test, detecting $62.5 \%$ of patients with RA. Previous studies reported anti-CCP antibodies in $47 \%-63 \%$ of patients with recent-onset RA, whereas anti-citrullinated vimentin antibodies have been reported in only one fifth of RA patients with early disease by immunoblotting $[13,15]$, thus indicating a superior performance of the anti-MCV ELISA in this early-disease group compared with the immunoblotting technique $[8,9,26,32]$. Besides, the presence 
of anti-CCP antibodies has been shown to precede clinical onset of RA, and one might speculate that anti-MCV antibodies are also present in pre-disease serum samples [33]. Therefore, we cannot exclude the possibility that some of our antiMCV (high)-positive patients without RA might develop RA in the future. In that case, the true degree of specificity of antiMCV testing in this cohort might be underestimated [1].

The major limitations of our study are the small number of RA patients with early disease $(n=23)$ and the lack of follow-up data of the patients with non-RA. Prospective studies addressing the course of patients with undifferentiated early arthritis and long-term follow-up of the anti-MCV-positive patients with non-RA are necessary to evaluate the prognostic and diagnostic value of this test for patients with early RA. Because chart reviews partially lacked data of acute-phase reactants and clinical assessments, we did not investigate possible associations of the anti-MCV titer and other laboratory parameters and the clinical disease activity. Also, comparisons of the diagnostic value of anti-MCV with lgM-RF should be interpreted with caution due to the retrospective and incomplete retrieval of the IgM-RF. The sensitivity and specificity of IgM-RF in our present study are nevertheless consistent with published data [7].

\section{Conclusion}

Autoantibodies to citrullinated proteins are specific for the diagnosis of RA. The anti-MCV ELISA is a novel, commercially available test system for the detection of antibodies directed against a modified citrullinated vimentin that demonstrates comparable overall diagnostic performance in relation to the anti-CCP2 assay according to the ROC analysis, with the calculated AUCs of 0.824 versus 0.818 , respectively. In the highspecificity range of both tests, which is clinically the most relevant, the anti-CCP2 ELISA appears to be superior to the antiMCV assay.

\section{Competing interests}

The authors declare that they have no competing interests.

\section{Authors' contributions}

$\mathrm{C}$ Dejaco, C Duftner, MS, and $\mathrm{MH}$ diagnosed and treated the patients. $\mathrm{MH}, \mathrm{C}$ Dejaco, $\mathrm{HL}$, and $\mathrm{C}$ Duftner designed the study and performed the analyses. WK carried out the ELISAs. MS helped to coordinate the study. All authors were involved in drafting the manuscript and read and approved the final version.

\section{Additional files}

The following Additional file is available online:

\section{Additional File 1}

A TIFF file showing a flow chart of enrolment and outcomes.
See http://www.biomedcentral.com/content/ supplementary/ar2008-S1.tiff

\section{Acknowledgements}

This work was supported by Innsbruck Medical University, the 'Verein zur Förderung der wissenschaftlichen Ausbildung und Tätigkeit von Südtirolern an der Universität Innsbruck' (to C Dejaco), and the Tyrolean Research Funds (to C Duftner).

\section{References}

1. Lawrence RC, Helmick CG, Arnett FC, Deyo RA, Felson DT, Giannini EH, Heyse SP, Hirsch R, Hochberg MC, Hunder GG, et al:: Estimates of the prevalence of arthritis and selected musculoskeletal disorders in the United States. Arthritis Rheum 1998, 41:778-799.

2. Arnett FC, Edworthy SM, Bloch DA, McShane DJ, Fries JF, Cooper NS, Healey LA, Kaplan SR, Liang MH, Luthra HS, et al.: The American Rheumatism Association 1987 revised criteria for the classification of rheumatoid arthritis. Arthritis Rheum 1988, 31:315-324.

3. Visser H, le Cessie S, Vos K, Breedveld FC, Hazes JM: How to diagnose rheumatoid arthritis early: a prediction model for persistent (erosive) arthritis. Arthritis Rheum 2002, 46:357-365.

4. Sebbag M, Simon M, Vincent C, Masson-Bessiere C, Girbal E, Durieux JJ, Serre G: The antiperinuclear factor and the so-called antikeratin antibodies are the same rheumatoid arthritis-specific autoantibodies. J Clin Invest 1995, 95:2672-2679.

5. Girbal-Neuhauser E, Durieux JJ, Arnaud M, Dalbon P, Sebbag M, Vincent C, Simon M, Senshu T, Masson-Bessiere C, Jolivet-Reynaud $\mathrm{C}$, et al:: The epitopes targeted by the rheumatoid arthritis-associated antifilaggrin autoantibodies are posttranslationally generated on various sites of (pro)filaggrin by deimination of arginine residues. J Immunol 1999, 162:585-594.

6. Schellekens $\mathrm{GA}$, de Jong $\mathrm{BA}$, van den Hoogen $\mathrm{FH}$, van de Putte LB, van Venrooij WJ: Citrulline is an essential constituent of antigenic determinants recognized by rheumatoid arthritisspecific autoantibodies. J Clin Invest 1998, 101:273-281.

7. Herold M, Boeser V, Russe E, Klotz W: Anti-CCP: history and its usefulness. Clin Dev Immunol 2005, 12:131-135.

8. Vallbracht I, Rieber J, Oppermann M, Forger F, Siebert U, Helmke $\mathrm{K}$ : Diagnostic and clinical value of anti-cyclic citrullinated peptide antibodies compared with rheumatoid factor isotypes in rheumatoid arthritis. Ann Rheum Dis 2004, 63:1079-1084.

9. Saraux A, Berthelot JM, Devauchelle V, Bendaoud B, Chales G, Le Henaff C, Thorel JB, Hoang S, Jousse S, Baron D, et al:: Value of antibodies to citrulline-containing peptides for diagnosing early rheumatoid arthritis. J Rheumato/ 2003, 30:2535-2539.

10. Vossenaar ER, Venrooij WJ: Anti-CCP antibodies, a specific marker for (early) rheumatoid arthritis. Clin Appl Immunol Rev 2004, 4:239-262.

11. Despres N, Boire G, Lopez-Longo FJ, Menard HA: The Sa system: a novel antigen-antibody system specific for rheumatoid arthritis. J Rheumatol 1994, 21:1027-1033.

12. Escalona M, Lopez-Longo FJ, Gonzalez CM, Monteagudo I, Rodriguez-Mahou M, Grau R, Carreno L: Anti-Sa sera from patients with rheumatoid arthritis contain at least 2 different subpopulations of anti-Sa antibodies. J Rheumatol 2002, 29:2053-2060.

13. Hueber W, Hassfeld W, Smolen JS, Steiner G: Sensitivity and specificity of anti-Sa autoantibodies for rheumatoid arthritis. Rheumatology 1999, 38:155-159.

14. Goldbach-Mansky R, Lee J, McCoy A, Hoxworth J, Yarboro C, Smolen JS, Steiner G, Rosen A, Zhang C, Menard HA, et al:: Rheumatoid arthritis associated autoantibodies in patients with synovitis of recent onset. Arthritis Res 2000, 2:236-243.

15. Hayem G, Chazerain $P$, Combe $B$, Elias $A$, Haim $T$, Nicaise $P$, Benali K, Eliaou JF, Kahn MF, Sany J, et al.: Anti-Sa antibody is an accurate diagnostic and prognostic marker in adult rheumatoid arthritis. J Rheumatol 1999, 26:7-13. 
16. El-Gabalawy HS, Wilkins JA: Anti-Sa antibodies: prognostic and pathogenetic significance to rheumatoid arthritis. Arthritis Res Ther 2004, 6:86-89.

17. Ota F, Maeshima A, Yamashita S, Ikeuchi H, Kaneko Y, Kuroiwa T, Hiromura K, Ueki K, Kojima I, Nojima Y: Activin A induces cell proliferation of fibroblast-like synoviocytes in rheumatoid arthritis. Arthritis Rheum 2003, 48:2442-2449.

18. Marinova-Mutafchieva L, Taylor P, Funa K, Maini RN, Zvaifler NJ: Mesenchymal cells expressing bone morphogenetic protein receptors are present in the rheumatoid arthritis joint. Arthritis Rheum 2000, 43:2046-2055.

19. Xue C, Takahashi M, Hasunuma T, Aono H, Yamamoto K, Yoshino $\mathrm{S}$, Sumida T, Nishioka K: Characterisation of fibroblast-like cells in pannus lesions of patients with rheumatoid arthritis sharing properties of fibroblasts and chondrocytes. Ann Rheum Dis 1997, 56:262-267.

20. Vossenaar ER, Radstake TR, van der Heijden A, van Mansum MA, Dieteren C, de Rooij DJ, Barrera P, Zendman AJ, van Venrooij WJ: Expression and activity of citrullinating peptidylarginine deiminase enzymes in monocytes and macrophages. Ann Rheum Dis 2004, 63:373-381.

21. Bird HA, Esselinckx W, Dixon AS, Mowat AG, Wood PH: An evaluation of criteria for polymyalgia rheumatica. Ann Rheum Dis 1979, 38:434-439.

22. Wright V, Moll JMH: Psoriatic arthritis. In Seronegative Polyarthritis Edited by: Wright V, Moll JMH. Amsterdam: North Holland Publishing Company; 1976:169-223.

23. van der Linden S, Valkenburg HA, Cats A: Evaluation of diagnostic criteria for ankylosing spondylitis. A proposal for modification of the New York criteria. Arthritis Rheum 1984, 27:361-368.

24. Dougados $M$, van der Linden $S$, Juhlin $R$, Huitfeldt $B$, Amor $B$, Calin A, Cats A, Dijkmans B, Olivieri I, Pasero G, et al.: The European Spondylarthropathy Study Group preliminary criteria for the classification of spondylarthropathy. Arthritis Rheum 1991, 34:1218-1227.

25. Egerer K, Bang H, Lathke K, Gauliard A, Feist E, Rudolph PE, Berg W, Burmester GR: A new powerful marker for the diagnosis and prognosis of rheumatoid arthritis - anti-CVM (anti-citrullinated vimentin mutated) antibodies [abstract]. Arthritis Rheum 2005, 52(Suppl S):S118.

26. Dubucquoi S, Solau-Gervais E, Lefranc D, Marguerie L, Sibilia J, Goetz J, Dutoit V, Fauchais AL, Hachulla E, Flipo RM, et al.: Evaluation of anti-citrullinated filaggrin antibodies as hallmarks for the diagnosis of rheumatic diseases. Ann Rheum Dis 2004, 63:415-419.

27. Egsmose C, Lund B, Borg G, Pettersson H, Berg E, Brodin U, Trang L: Patients with rheumatoid arthritis benefit from early 2nd line therapy: 5 year followup of a prospective double blind placebo controlled study. J Rheumatol 1995, 22:2208-2213.

28. Quinn MA, Emery $P$ : Potential for altering rheumatoid arthritis outcome. Rheum Dis Clin North Am 2005, 31:763-772.

29. Symmons DP, Jones MA, Scott DL, Prior P: Longterm mortality outcome in patients with rheumatoid arthritis: early presenters continue to do well. J Rheumatol 1998, 25:1072-1077.

30. Mimori T: Clinical significance of anti-CCP antibodies in rheumatoid arthritis. Intern Med 2005, 44:1122-1126.

31. Menard HA, Lapointe E, Rochdi MD, Zhou ZJ: Insights into rheumatoid arthritis derived from the Sa immune system. Arthritis Res 2000, 2:429-432.

32. Raza K, Breese M, Nightingale P, Kumar K, Potter T, Carruthers DM, Situnayake D, Gordon C, Buckley CD, Salmon M, et al.: Predictive value of antibodies to cyclic citrullinated peptide in patients with very early inflammatory arthritis. J Rheumatol 2005, 32:231-238.

33. Berglin E, Padyukov L, Sundin U, Hallmans G, Stenlund H, Van Venrooij WJ, Klareskog L, Dahlqvist SR: A combination of autoantibodies to cyclic citrullinated peptide (CCP) and HLADRB1 locus antigens is strongly associated with future onset of rheumatoid arthritis. Arthritis Res Ther 2004, 6:R303-308. 